\title{
Self-Organising Networks in Complex Infrastructure Projects
}

\author{
Stephen Pryke, Sulafa Badi, Balamurugan Soundararaj and Simon Addyman \\ The Bartlett School of Construction \& Project Management, University College London, 2nd Floor, $1-19$ \\ Torrington Place, London, WClE $7 \mathrm{HB}$
}

\section{INTRODUCTION}

Large infrastructure projects are characterized by technical, organisational and environmental complexity (Bosch-Rekveldt et al., 2011). Organisational complexity particularly arises from the need to manage the relationships among a large number of actors with multiple interests and objectives (Flyvbjerg, 2009). Infrastructure projects are also subject to multiple types of uncertainties: internally - such as duration estimations, firm's financial capabilities, and efficiency and performance of project participants; and externally - such as governmental and regulatory change, economic turbulence, legal changes, and natural disasters (Love et al., 2002). In an effort to manage project uncertainty clients tend to allocate risk in accordance with functional contract transactions, which often results in situations where behaviours become more aligned with resolving contractual obligations than the resolution of the key issues. Traditional organisational and contractual models of infrastructure project delivery simply accept this situation, which often results in limitations in achieving radical and sustained improvements in performance.

While traditional project management literature has placed great emphasis on technical issues such as planning, scheduling, risk analysis and project management techniques (Winter et al., 2006), there have been recent calls for more attention to be placed on the 'relational', 'human' and 'social' 
dimensions of project management (Winter et.al., 2006; Hanisch and Wald, 2011, Meng, 2012). This is largely driven by the growing recognition of 'informal' and relational forms of governance in projects. Increasingly, contemporary management scholars are viewing projects as complex networks of multiple interdependent actors (Dubois and Gadde, 2000; Eloranta et al., 2006). Indeed, despite the significant attention placed on establishing formal organisational and contractual hierarchies in large, complex infrastructure projects, much of the decision making related to project uncertainties are made through non-contractual, multi-functional networks of individuals temporarily brought together through project-related common interest or tasks.

Network theory is a dominant theoretical paradigm in management research as well as other disciplines including communication, knowledge transfer, marketing, economics, anthropology, epidemiology and organisational studies (Borgatti and Foster, 2003; Brass et al., 2004; Freeman, 2004; Contractor et al., 2006). Network theory offers a powerful analytical tool for capturing, analysing and visualising complex infrastructure projects and their interacting organisations. In the construction industry domain, Loosemore (1999) was among the first to adopt SNA in his study of communication networks under situations of crisis in UK construction. Likewise, Pryke (2004; 2005; 2012) applied SNA within construction projects in the UK, France and China, examining the effects of changes in procurement strategy on project governance and project management systems. Ouwerkerk (2001) used SNA to map project relationships for effective risk identification and management, while in the work of El-Sheikh and Pryke (2010), SNA supported the identification of communication gaps in a construction project. More recently, Chowdhury et al (2011) used a representative single case study of a Public Private Partnership (PPP) project to highlight the benefits of using SNA in deepening the understanding of the structuring of PPP 
arrangements and how the structure of the network emerges from the relationships between project stakeholders. Hossain (2009) also used SNA to examine the relationship between an actor's structural position in the communication network and his or her ability to coordinate project activities. His findings highlighted the importance of centrally positioned actors performing a large proportion of the coordination activities within the network.

Taken together, the studies discussed above underline the benefits of adopting a network view to the study of construction projects. In particular, a network perspective allows the comparison of the formally prescribed project organisation with the actual organisation and underlines the importance of the informal social structures that operate "behind the chart" in large infrastructure project organisations. It also provides a deeper understanding of the various informal network roles that actors play depending on their network position. Having said that, studies adopting a networkanalytical perspective remain scarce in the project management domain (Kratzer et al., 2010; Hossain and $\mathrm{Wu}, 2009)$ compared to other management disciplines (Balkundi and Harrison, 2006). Therefore, there is a need for more empirical studies on project networks.

This study extends previous work on project networks (Pryke, 2004; 2005; 2012) and is based on a pilot study conducted on a large and complex infrastructure project, the Bank Station Capacity Upgrade Programme, with the purpose of obtaining initial understanding of the structure and the functioning of the network. Particularly, we sought answers to the following questions:

1. Are the communication routes, strengths and direction optimum in relation to the functions of the network? 
2. Which actors are critical for fostering collaboration?

3. Which actors behave as brokers, establishing and maintaining connections that improve or restrict the flow of communication?

Based on quantitative network data collected through an online questionnaire with 63 project participants, the study examined four major network characteristics, including connectivity (Degree centrality), influence (Eigenvector Centrality), brokerage (Betweenness Centrality) and the existence of communities. The study demonstrates the usefulness of SNA in facilitating a better understanding of how infrastructure project networks are functioning and providing valuable information to project managers. In particular, it exposes dysfunctions in the project network and allows for the development of network-based interventions to design team structures that facilitate successful collaboration.

We begin this paper by providing an introduction to SNA and outline the main structural elements and analytical measures. We then describe the case study and discuss the findings of the empirical investigation. The conclusion summarises the findings; discusses the contribution of the approach to management practice and underlines directions for future research on project networks. 


\section{CONCEPTUAL UNDERPINNINGS}

\section{Network structure}

Wasserman and Faust (1994) describe a social network as a set of actors connected through a set of clearly specified relationships. These relationships can be directed in that they flow from one actor to the other, such as information, trust and affection, or undirected; sharing an office for example. Network theory attempts to explain the effects that different structural properties can have on the actors. A key dimension of social networks is density, which represents the proportion of all possible ties that are actually present, calculated by the number of ties divided by the total number of possible ties. The values range between 0 and 1 where 0 denotes that network actors are unconnected whilst 1 indicates full connectivity. Density is an indicator of the speed at which information diffuses in the social network and the extent to which network actors can reach each other. It also represents ‘cohesion' - a reflection of redundancy taking place within a group. Higher cohesion, which is the existence of a large proportion of redundant ties between actors, is often associated with increased team performance (Beal et al., 2003; Evans and Dion, 2012). This is explained by cohesion representing many trusted relationships through which valuable resources such as knowledge, information and opportunities can flow. The work of Wise (2014), however, has contested this view, following a study of 180 teams of travel agents. His findings suggested that an inverse curvilinear relationship may exist between team cohesion and team performance. Group performance was found to be maximised at an optimal point of group cohesion, any 
decrease or increase beyond this point will result in suboptimal performance. He argues that too much team cohesion can lead to negative results, such as 'group think' and limited innovation.

Geodesic distance is another network analytical measure that indicates the distance between two nodes in the network in question, calculated by the minimum number of ties that must be crossed to get from one actor to another. A large geodesic distance between two actors would indicate that several intermediary actors would have to transfer information between the communication originator and the receiver. This may result in extended time periods for processing the information, higher potential for miscommunications, and an increase in the boundaries between the two actors.

Finally, the property of community structure identifies network actors that are joined together in densely connected groups with looser connections to other parts of the network. Communities may form based on common interest, occupation or co-location and identifying these sub-structures can offer insight into how network function and typology may affect each other. This is particularly important for project managers as previous research, such as that of Donaldson (2001), have shown that social network typology can be optimised to improve the functioning of the network and increase its overall performance.

\section{Network position}

Network theory postulates that the position an actor occupies in a network can enhance or constrain his access to valued network resources. An isolated position on the periphery of the network is generally regarded as unfavourable as it offers limited opportunity to access other network actors 
and their resources. On the other hand, occupying a central position is often associated with status, power and influence as it provides the actor with direct access to many other network members and increases his visibility.

Three different concepts of centrality are traditionally differentiated in network analysis (Freeman, 1979). Degree centrality is an indicator of the 'connectivity' of an actor, based on measuring an actor's direct connections. It is categorised into In-degree and Out-degree centrality, depending on the tie's direction. In-degree measures 'receptivity', whilst out-degree is a measure of 'expansiveness'. Degree Indicates power within one's own group, but not necessarily beyond that (McCulloh et al., 2013).

Another important measure is eigenvector centrality, an indicator of 'influence', which identifies actors who are well connected to other well-connected actors. Actors with high eigenvector centrality have the power to connect to other influential individuals and have the power to build norms and expectations that others in their group will relate to (McCulloh et al., 2013).

Finally, betweenness centrality is an indicator of 'power', 'control potential', 'brokerage' and 'coordination activity' based on identifying actors on the path between most of the other nodes in the network (Alojairi and Safayeni, 2012). Actors with high betweenness have the best opportunity to filter or change information flowing to others in the network, thus information can be delayed, changed, or stopped at these points in the network. They could act as funnels through which most communication travel across the network, or as 'choke' points filtering or passing a particular view of the information, or even misinformation. Some nodes may exhibit high betweenness but lower 
degree centrality, and often termed 'boundary spanners', they are key individuals who connect otherwise disconnected groups and their removal may fragment the network and cease the flow of information.

\section{Summary}

In this research study we propose that the four concepts of connectivity, communities of densely connected actors, influence, and brokerage outlined above are instrumental in enabling a superior view of the functioning of large infrastructure project networks. The network along with the communities will examine the overall network structure and determine whether the communication routes, strengths and direction optimum in relation to the functions of the network. Centrality measures indicating connectivity, influence and brokerage will identify important actors who are critical for fostering collaboration.

\section{METHODOLOGY}

SNA is fundamentally a positivist approach that favours a structuralist perspective, mainly due to its emphasis on understanding the functioning of systems through the mapping of the interrelationships between its members. SNA requires, as a starting point of analysis, a holistic and rigorous description of relationship patterns in order to structure a useful understanding (Knoke and Young, 2008). A case study approach was adopted on this study with an aim to investigate informal project delivery related communication and collaboration in a complex and temporary project environment, which necessitates an in-depth analysis of the specific project in its context. 


\section{Context: The Bank Station Capacity Upgrade Programme}

We study the case of the London Underground Limited Bank Station Capacity Upgrade Programme. The project is unique in that it is part of a number of pilot projects that aimed to promote collaborative working arrangements in order to drive down the cost of risks associated with successful project delivery. The case study is the subject of a Knowledge Transfer Partnership (KTP) between UCL and Transport for London (TfL) which is part funded by the Technology Strategy Board (now Innovate UK) and contributes to the collaborative work of Infrastructure UK (IUK).

At an estimated cost of $£ 563 \mathrm{~m}$, the project was initially launched in 2003 . It went through the development of a number of options before arriving at a base case in 2011 and entered tender process in 2012. The conceptual design was completed and application for permission under Transport and Works Act Order was submitted in September 2014, while the construction is expected to start in spring 2016. The project at the conceptual design stage involved contributions from more than 6 organisations and more than 250 personnel across various teams and roles. The contractual structure consists of the client (Transport for London) and three tiers of contractors as shown in Figure 1. The formal organisational structure for the project is linear and hierarchical with a limited degree of mixed teams and responsibilities as shown in Figure 2. 


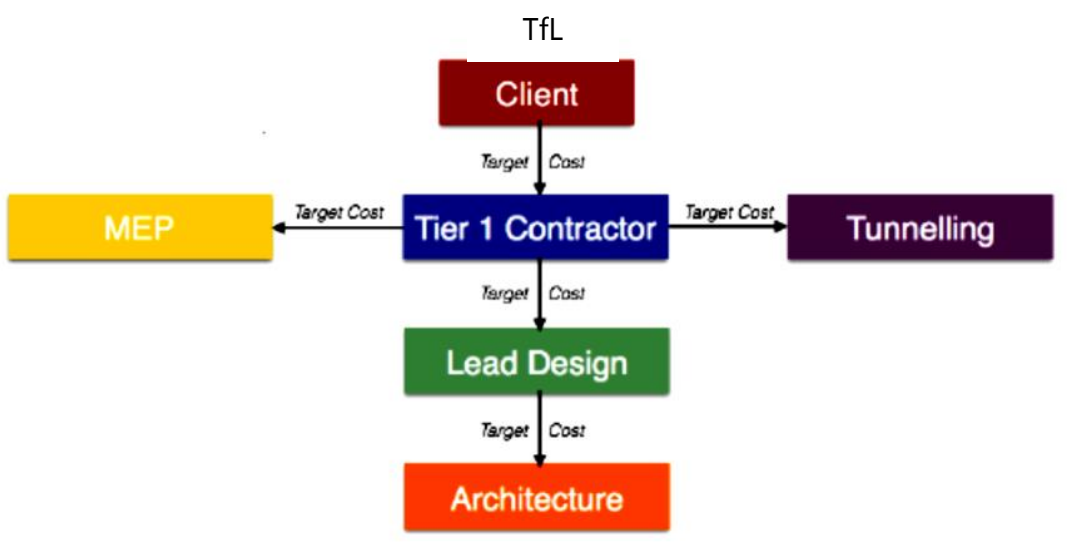

Figure 1: The contractual structure between organisations for Bank Station Capacity Upgrade Programme (April 2014) 


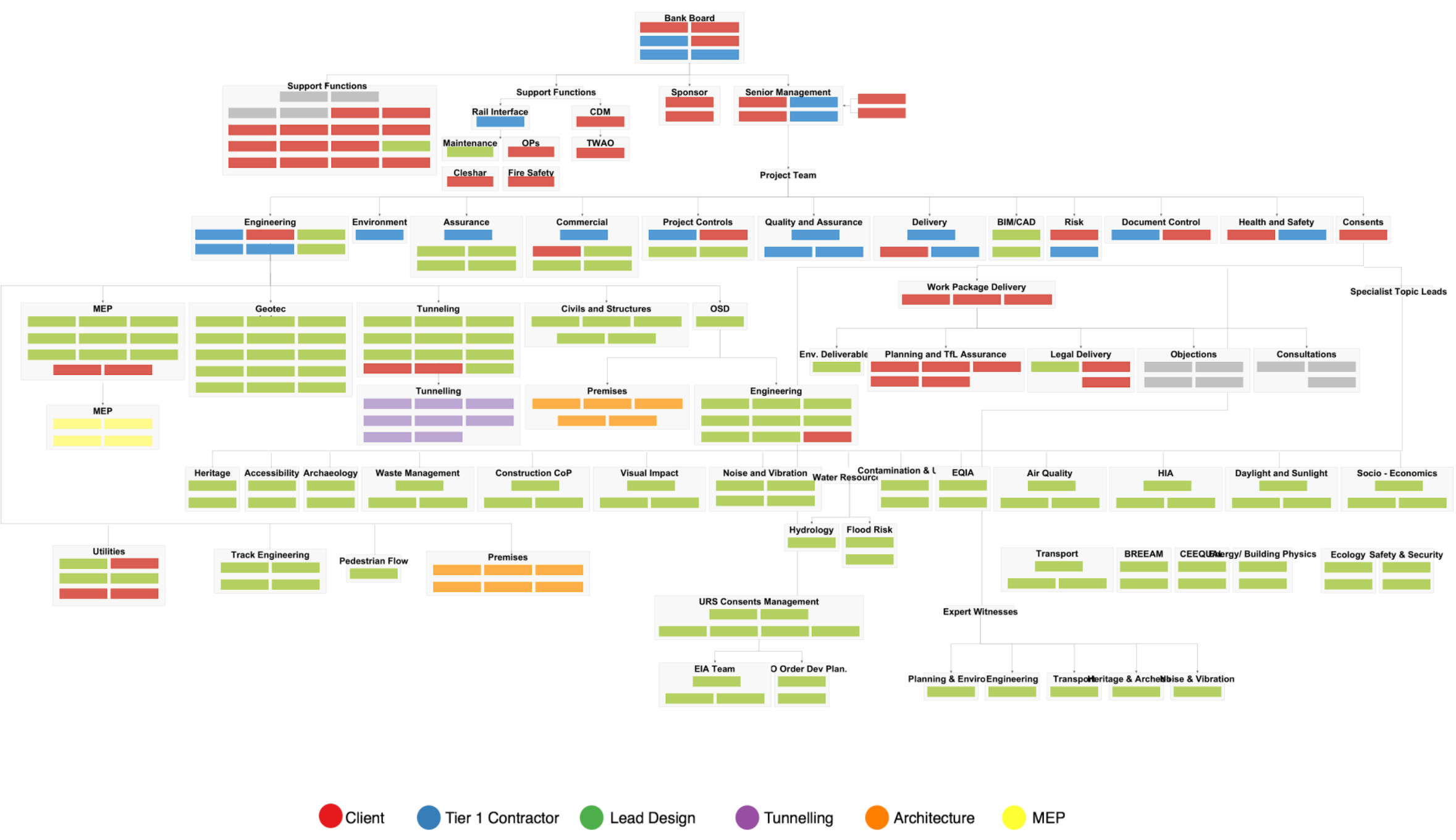

Figure 2: The formal organisation of individuals and roles for Bank Station Capacity Upgrade Programme (April 2014) 


\section{Data collection}

Data collection took place between January 2014 to April 2014 during the design and approvals stage of the project. The boundaries of the network were established as the team involved in the design of the central line escalators in relation to impacts on settlements and reaching agreement on UMC/LMC, switchgear and maintenance space proofing requirements while developing the conceptual design for the project.

The data collected represent networks of actors involved in resolving issues during the design of the Central line escalators. Data was collected through an online questionnaire from 60 project actors. Actors were asked to identify the individuals with whom they communicated with in relation to issue resolution. Email, phone call, letter, or face-to-face conversations are collectively represented as a relationship between two actors. Likert scale values were recorded (low, medium or high, scoring one, two or three respectively) for frequency and quality of the communication. Quality was measured using five measures: importance, clarity, accuracy, timeliness, reliability and understanding. The scores for frequency and quality were multiplied and used, following Pryke (2012), as a proxy for tie strength. Table 1 lists the main questionnaire items, while Figure 3 illustrates the survey format and user interface accessible to the respondents.

\section{Table 1: Questionnaire items}

\begin{tabular}{ll}
\hline Questions & Details \\
\hline $\begin{array}{l}\text { What are the details of the } \\
\text { respondent? }\end{array}$ & Name, Organisation, role, time spent in Bank \\
$\begin{array}{l}\text { Was he/she involved in the design of } \\
\text { the Central line escalators? }\end{array}$ & Yes/ No \\
\hline
\end{tabular}




\begin{tabular}{ll}
$\begin{array}{l}\text { Whom he/she communicated in } \\
\text { resolving the issues during the } \\
\text { design of the Central line } \\
\text { escalators? }\end{array}$ & $\begin{array}{l}\text { Selected from an expandable list of individuals } \\
\text { [yes/no] }\end{array}$ \\
$\begin{array}{l}\text { What was the quality of } \\
\text { communication for each one? }\end{array}$ & $\begin{array}{l}\text { Frequency [Nominal], Importance, Clarity, } \\
\text { Accuracy, Timeliness, Reliability, Understanding, } \\
\text { [Ordinal -2:2] }\end{array}$ \\
\hline
\end{tabular}

Source: original

Several challenges were experienced during the data collection process. First, the initial response rate for the survey was low. A number of measures including designing an easier questionnaire; conducting drop-in sessions, following up with target respondents over email and in person were taken up to improve the rate to $73 \%$. Second, the survey adopted the 'snow-balling method' where participants were identified progressively as they were added to the list by early completers of the survey. In hindsight, it would have been better if the list of target respondents was complete with their organisations, roles and contact details before the start of the survey so that they could have been pre-filled in the survey responses. There were also difficulties for respondents to remember individuals by names accurately. Third, even after simplification, the questionnaire was complex to use. The possibility of an integrated system of data collection, which is built on top of a database of all individuals in the project, with a further simplified survey format, could be explored for overcoming these problems. 


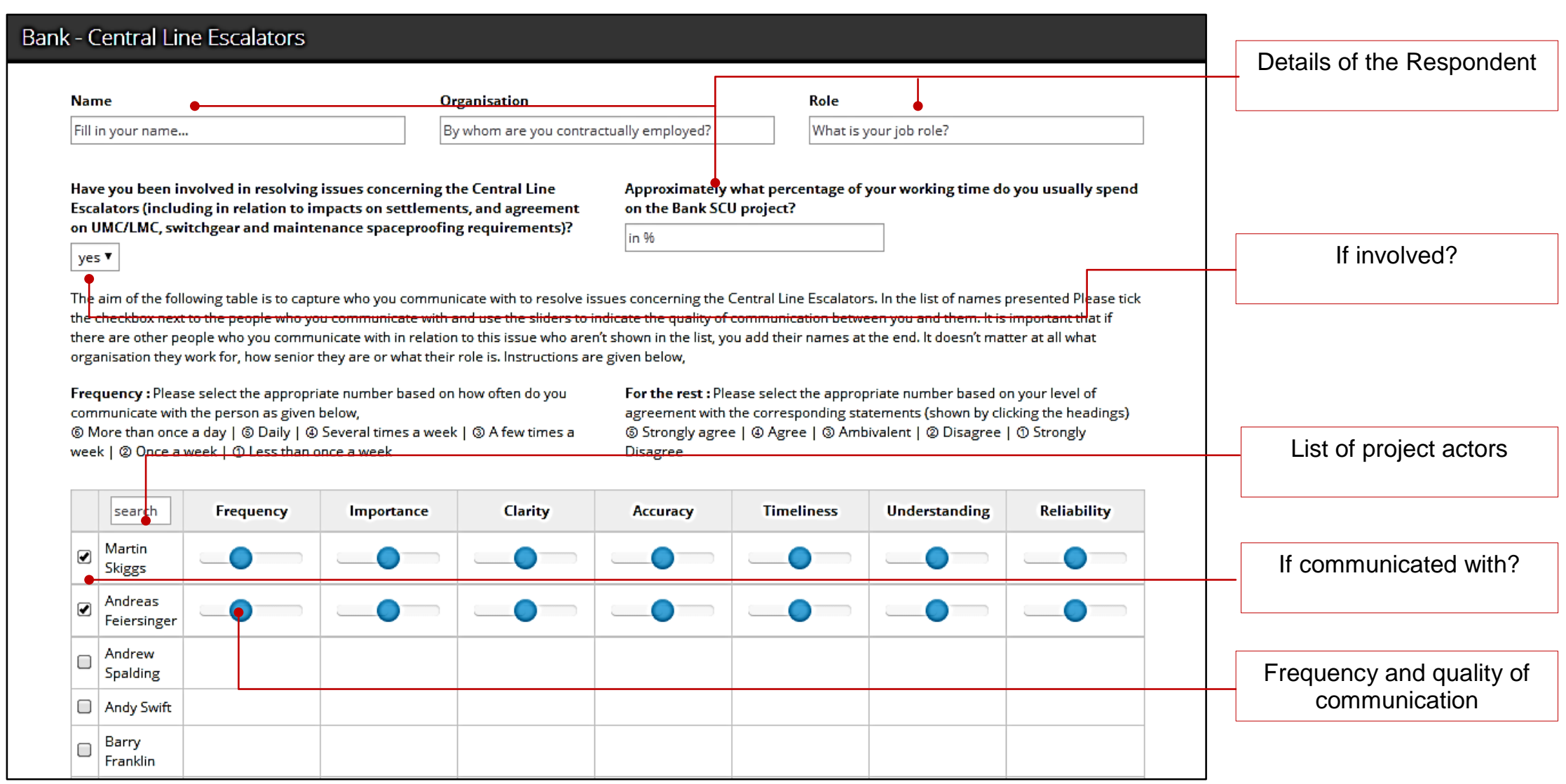

Figure 3: The survey format and user interface 


\section{Data Analysis}

The data collected through the online questionnaire is stored in an SQL database with a structure as shown in Figure 4. This data is retrieved using PHP Hypertext Processor and combined into one network by merging the overlapping links in each survey response and calculating weights of the links from the responses on frequency and quality of the links.

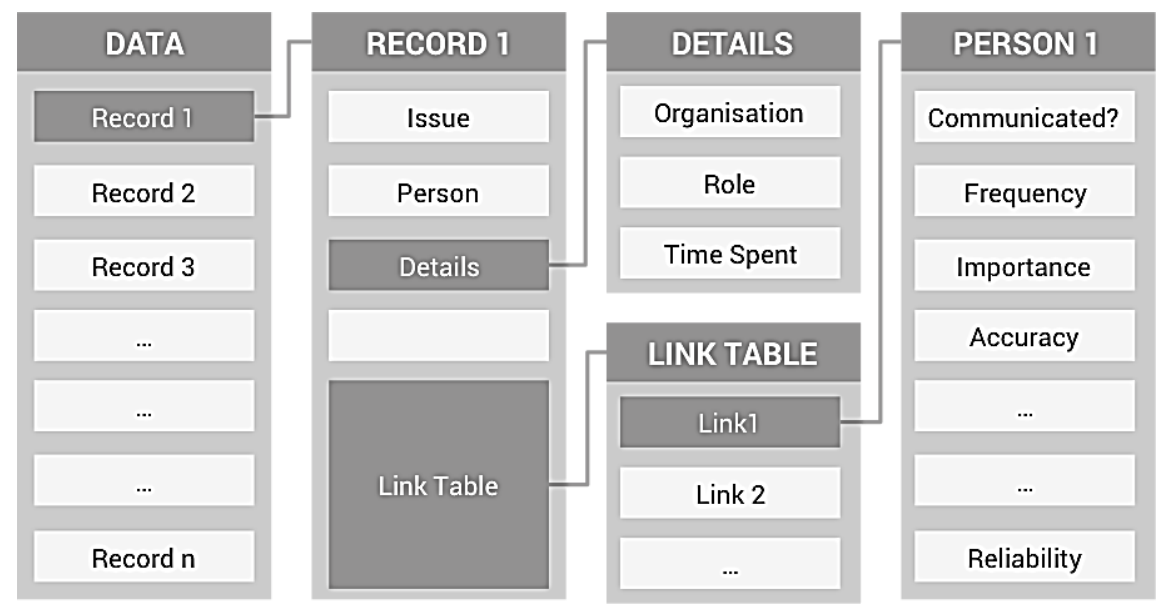

Figure 4: Structure of the data collected

While creating a weighted network, the link weight is determined from the information collected on the quality of the link and was normalised to a continuous value between 0 and 1 where, 0 denotes no link and 1 denotes the strongest possible link between the corresponding nodes. In this case the strength of node is defined by two variables Frequency and Quality. The strength of communication between the actors $\mathrm{i}$ and $\mathrm{j}$ is thus expressed as, 


$$
\begin{gathered}
E_{i j}=F_{i j} \times Q_{i j} \\
\text { Where, } F_{i j}=\frac{f_{i j}}{6} \text { and } Q_{i j}=\frac{\sum q_{i j}}{30}
\end{gathered}
$$

Where $F_{\mathrm{ij}}$ is the frequency of communication normalised to be between $0-1$ and $\mathrm{Q}_{\mathrm{ij}}$ is the quality of each communication which is the mean of all six individual parameters $\mathrm{q}_{\mathrm{ij}}$ (shown in table 1) normalised to be between $0-1$. Theoretically, this process could be further expanded through a weighted average for each individual parameter but in this analysis, for simplicity, all parameters are considered to be equally important in defining the quality of a communication. The final value $E_{i j}$ is calculated for all the links in each record in the data.

While combining all the responses into one network the links are merged to form a directed network reflecting the direction of communication between project actors. It is important to note that the direction of links in the resulting network is not the direction of the information flow but the perceived existence of communication between the actors as per the origin. In the case where there is no reciprocal link for a link between two actors, the trust on information on the available link is reduced. This process can be described as below,

$$
i f\left(E_{j i}=0\right) \text { then } E_{i j}=E_{i j} \times a
$$


Where ' $a$ ' is the constant factor assumed to adjust the weights of the links without reciprocal links. A value of a $10 \%$ is assumed for ' $a$ '. This can be made more accurate by relating this to node characteristics and aggregate network measures in further studies. The whole merging process is shown in Figure 5a and 5b.

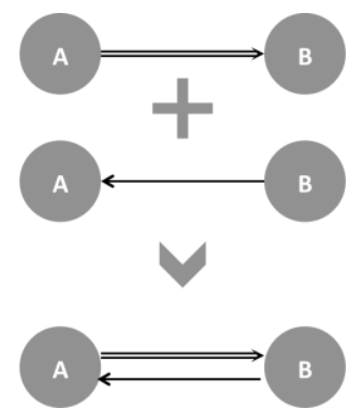

Figure 5a: Overlapping links are merged to form a directed network between actors

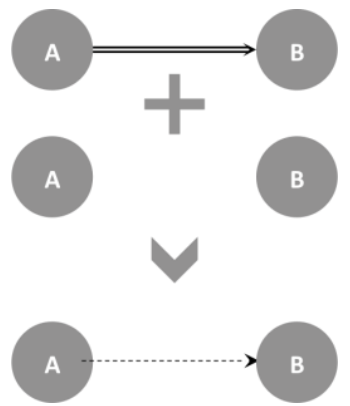

Figure 5b: Links without reciprocal links are adjusted with a constant so that their impact is less on the overall network.

The resulting network is then analysed using igraph Library (Csardi and Nepusz, 2006) in $\mathrm{R}$ Programming language to find out characteristics of the network - Density, Diameter and Average Path Length (West, 1996) and of the actors - Degree Centrality, Betweenness Centrality (Freeman, 1979; Brandes, 2001) Eigenvector Centrality (Bonacich, 1987) and Communities (Pons and Latapy, 2014).

After the analysis the graph is exported to a tabular format and visualised using Gephi. A force directed layout - Force Atlas 2 (Jacomy et al., 2014) is used for all the visualisations except for 
the ones showing community structure, where a manually created layout is used. These visualisations are then used for interpretations in consultation with key individuals in senior management for Bank Station Capacity Upgrade Programme.

\section{RESULTS}

In this section we discuss the results of the network study, which took an 'X-ray snap shot' reflecting the state of the information exchange network between individuals involved in solving a specific issue during the conceptual design stage of the project in early 2014 . We conducted a quantitative analysis of these networks, examining their structure, prominent actors, communities and a comparison with the formal organisational and contractual structure.

\section{Network structure}

The complete information exchange network created from the data is displayed in Figure 6 below. The network contains 270 links, the arrow-heads indicating the direction of information flow as perceived by the actor who is the origin, which can be unidirectional or bidirectional. 


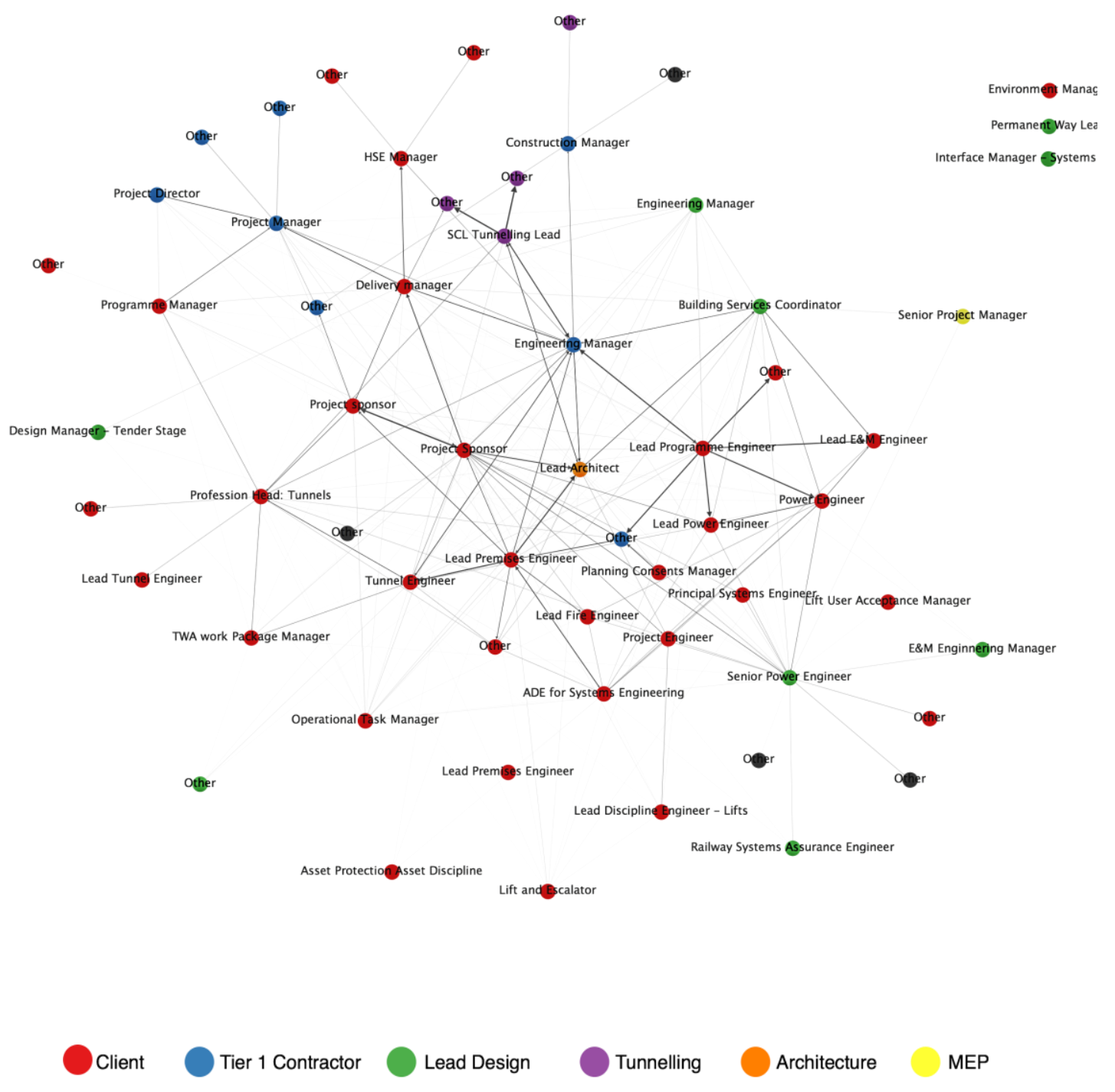

Figure 6: Information exchange network 
The network has a density of $7.6 \%$ and shows a core - periphery structure with some 'small-world' properties, particularly clustering and short average shortest path lengths. Since this was an engineering problem, the core of the network consists of the lead managers of the engineering disciplines and the project sponsor. The senior management team is at the periphery of the network not involved in the bulk of the information exchange. The network also has few actors with a large amount of connectivity and influence in the network.

Because of the above mentioned properties, even with a low density, the structure of the network is such that any two actors are connected within a maximum of 5 steps (or links) and an average of 2.23 steps. The average geodesic distance is relatively small which indicates that information travels quickly as actors need to cross few links in order to communicate with other actors. This, in a design environment, may indicate efficiency in communication and decision-making in the network since minimum amount of links is required to connect every member of the network closely.

There are three isolated actors in the network, which indicate that these poorly connected members of the project were not communicating with other members of the network in resolving this particular issue in spite of being a part of the design team. However, it is worth noting that while these actors are isolates in the network under study, the actors maybe well connected in other networks that are not included in the scope of the current investigation. 


\section{Communities}

The analysis and identification of communities helps us to identify the underlying hidden project delivery structure of a network based on the smaller groups formed by individual relationships between actors. The number, size and connections of communities help to understand how project team members form informal groups to get the 'work done'. It is worth noting that these structures are self-organized and not designed by the project management team. The communities emerging in the networks could be encouraged by practices such as co-location, formal team definitions and resource sharing; or discouraged, depending on the context.

The communities in the network under investigation are shown in Figure 7. In the network we found three distinct communities consisting of individuals from different organisation but working under a same theme. The themes identified are, 'Doing', 'Decision-making' and 'Designing'. It is also notable that the communities are formed around certain actors of high influence. This has many implications for management in terms of organizing the project team in a collaborative environment. Firstly, the organisation of tasks and resources could be done while keeping these communities and associations in mind. Secondly, based on observed successful combinations, the management team could endeavour to replicate similar structures through the measures mentioned earlier.

This methodology can be improved by including the functional disciplines of the actors involved so that we can understand the multi-disciplinarily nature of these communities. In addition, through 
secondary information about the project, the management team could evaluate these communities and their importance.

\section{Network Position}

The position and importance of the actors in the network was measured in terms of the three different centralities described in Section 2.2. Table 2 displays the position/ centrality of all 60 actors within the network. The knowledge of position of actors within the network enables a better understanding of their relative importance in the network and also underlines any differences from the intended design. All three visualizations of the network based on the centralities were visually inspected for consistency within the actual practices in the project work through consultation with key individuals in the senior management team. The key observations and possible interpretations for the project are derived from the network.

\section{Connectivity}

Connectivity or Degree Centrality measures an actor's direct connections, representing his/her communication activity within the network. In our case high connectivity translates to the individuals who are the most visible to others or outspoken in the team. Since we are focusing on a network resolving a technical problem, we expect the individuals who are dealing with the technical aspects to be more significant in terms of connectivity. The network is shown in Figure 8. 
It was noticed that the above was not the case; the lead for Lifts and Escalators is at the periphery of the network with low connectivity while the Asset Discipline engineer for premises and systems were more prominent and central to the network. This along with the weak communication between the delivery manager and engineering manager were identified as problems in the network and were confirmed to have real impact in resolving the issue from the senior management team.

\section{Influence}

Influence or Eigenvector Centrality weights a node's degree according to the centrality of the nodes it is connected to. Thus, eigenvector contemplates the network's patterns holistically, by weighting both direct and indirect ties of every length (Borgatti, 2005). In our case high influence relates to the individuals who are close to highly connected individuals in the network. The network is shown in Figure 9. It was observed that the Tier-2 leads for functional disciplines have the most influence in the network compared with their positions in the organisational hierarchy, where we expect the Tier 1 managers to have the position.

It is worth noting that the senior management team sits on the periphery of the network while the project sponsors enjoy more influential positions. Considering the project is at conceptual design stage, the relevance of this phenomenon to project life cycle could be explored further. It was also noted that on the contrary to expectations, the Asset Protection and Discipline Engineer for maintenance has much less influence in the network solving a problem closely related to his responsibilities. 


\section{Brokerage}

Brokerage potential or Betweenness Centrality represents an index of potential control over communication, since actors with high betweenness can restrict the flow of information, otherwise known as brokerage (Kadushin, 2011). In our case high brokerage potential relates to individuals with very few strategic links between communities in the network. The network is shown in Figure 10. It was observed that critical individuals managing the process of resolving the issue have relatively high broker role in the network. It is also interesting to note that the Tier-2 leads on premises and tunnelling in spite of having significant influence in the network, have low broker roles in the network. In addition to this, significantly influential individuals in the network, such as the operational task manager, have limited broker role. This shows that the structure of the network makes these individuals bypass-able in terms of communication flow. This has both positive and negative implications for the resolution of the issue, which has to be explored further. 
Table 2: Centralities of actors within the information exchange network

\begin{tabular}{|c|c|c|c|c|c|}
\hline $\mathrm{Sn}$ & Role & Organisation & Connectivity & Influence & $\begin{array}{l}\text { Brokerag } \\
\mathrm{e}\end{array}$ \\
\hline 1 & Lead Architect & Architecture & 0.41 & 0.48 & 0.03 \\
\hline 2 & CPC Project Services & Client & 0.61 & 0.45 & 0.06 \\
\hline 3 & Programme Manager & Client & 0.25 & 0.23 & 0.01 \\
\hline 4 & Planning Consents Manager & Client & 0.05 & 0.01 & 0.00 \\
\hline 5 & Operational Task Manager & Client & 0.25 & 0.89 & 0.00 \\
\hline 6 & Profession Head: Tunnels & Client & 0.49 & 0.41 & 0.02 \\
\hline 7 & Power Engineer & Client & 0.39 & 0.13 & 0.03 \\
\hline 8 & ADE for Systems Engineering & Client & 0.32 & 0.07 & 0.01 \\
\hline 9 & Asset Protection Discipline & Client & 0.05 & 0.22 & 0.00 \\
\hline 10 & Environment Manager & Client & 0.00 & 0.00 & 0.00 \\
\hline 11 & Delivery manager & Client & 0.37 & 0.54 & 0.02 \\
\hline 12 & Tunnel Engineer & Client & 0.36 & 0.28 & 0.01 \\
\hline 13 & Lead Programme Engineer & Client & 0.41 & 1.00 & 0.06 \\
\hline 14 & HSE Manager & Client & 0.15 & 0.35 & 0.01 \\
\hline 15 & Project sponsor & Client & 0.32 & 0.31 & 0.01 \\
\hline 16 & TWA work Package Manager & Client & 0.19 & 0.36 & 0.00 \\
\hline 17 & Lead Discipline Engineer - Lifts & Client & 0.10 & 0.16 & 0.00 \\
\hline 18 & Lead Premises Engineer & Client & 0.41 & 0.39 & 0.03 \\
\hline 19 & Lead Premises Engineer & Client & 0.02 & 0.01 & 0.00 \\
\hline 20 & Lift User Acceptance Manager & Client & 0.02 & 0.01 & 0.00 \\
\hline 21 & Lift and Escalator & Client & 0.15 & 0.50 & 0.00 \\
\hline 22 & Project Engineer & Client & 0.12 & 0.27 & 0.00 \\
\hline 23 & Principal Systems Engineer & Client & 0.03 & 0.08 & 0.00 \\
\hline 24 & Lead Power Engineer & Client & 0.12 & 0.25 & 0.00 \\
\hline 25 & Lead Fire Engineer & Client & 0.08 & 0.15 & 0.00 \\
\hline 26 & Other & Client & 0.02 & 0.04 & 0.00 \\
\hline 27 & Other & Client & 0.10 & 0.32 & 0.00 \\
\hline 28 & Lead Tunnel Engineer & Client & 0.02 & 0.06 & 0.00 \\
\hline 29 & Other & Client & 0.02 & 0.06 & 0.00 \\
\hline 30 & Lead E\&M Engineer & Client & 0.07 & 0.11 & 0.00 \\
\hline 31 & Other / Unspecified & Client & 0.02 & 0.03 & 0.00 \\
\hline 32 & Other / Unspecified & Client & 0.02 & 0.05 & 0.00 \\
\hline 33 & Other / Unspecified & Client & 0.02 & 0.05 & 0.00 \\
\hline 34 & Other / Unspecified & Client & 0.02 & 0.01 & 0.00 \\
\hline 35 & Design Manager & Lead Design & 0.05 & 0.00 & 0.00 \\
\hline 36 & Interface Manager - Systems Integration & Lead Design & 0.00 & 0.00 & 0.00 \\
\hline 37 & Building Services Coordinator & Lead Design & 0.34 & 0.50 & 0.00 \\
\hline 38 & Railway Systems Assurance Engineer & Lead Design & 0.05 & 0.11 & 0.00 \\
\hline 39 & Permanent Way Lead & Lead Design & 0.00 & 0.00 & 0.00 \\
\hline 40 & Engineering Manager & Lead Design & 0.20 & 0.96 & 0.00 \\
\hline 41 & Senior Power Engineer & Lead Design & 0.54 & 0.08 & 0.04 \\
\hline 42 & E\&M Engineering Manager & Lead Design & 0.05 & 0.17 & 0.00 \\
\hline 43 & Other / Unspecified & Lead Design & 0.07 & 0.33 & 0.00 \\
\hline 44 & Senior Project Manager & MEP & 0.05 & 0.20 & 0.00 \\
\hline 45 & Other & Other / Unspecified & 0.02 & 0.07 & 0.00 \\
\hline 46 & Other / Unspecified & Other / Unspecified & 0.02 & 0.01 & 0.00 \\
\hline 47 & Other / Unspecified & Other / Unspecified & 0.02 & 0.01 & 0.00 \\
\hline 48 & Other / Unspecified & Other / Unspecified & 0.02 & 0.02 & 0.00 \\
\hline 49 & Project Director & Tier1 Contractor & 0.15 & 0.36 & 0.00 \\
\hline 50 & Project Manager & Tier1 Contractor & 0.36 & 0.52 & 0.02 \\
\hline 51 & Engineering Manager & Tier1 Contractor & 0.58 & 0.73 & 0.10 \\
\hline 52 & Construction Manager & Tier1 Contractor & 0.12 & 0.11 & 0.01 \\
\hline 53 & Other & Tier1 Contractor & 0.10 & 0.19 & 0.00 \\
\hline 54 & Other / Unspecified & Tier1 Contractor & 0.05 & 0.14 & 0.00 \\
\hline 55 & Other / Unspecified & Tier1 Contractor & 0.02 & 0.08 & 0.00 \\
\hline 56 & Other / Unspecified & Tier1 Contractor & 0.02 & 0.08 & 0.00 \\
\hline 57 & SCL Tunneling Lead & Tunneling & 0.31 & 0.54 & 0.02 \\
\hline 58 & Other / Unspecified & Tunneling & 0.03 & 0.17 & 0.00 \\
\hline 59 & Other / Unspecified & Tunneling & 0.02 & 0.10 & 0.00 \\
\hline 60 & Other / Unspecified & Tunneling & 0.02 & 0.02 & 0.00 \\
\hline
\end{tabular}




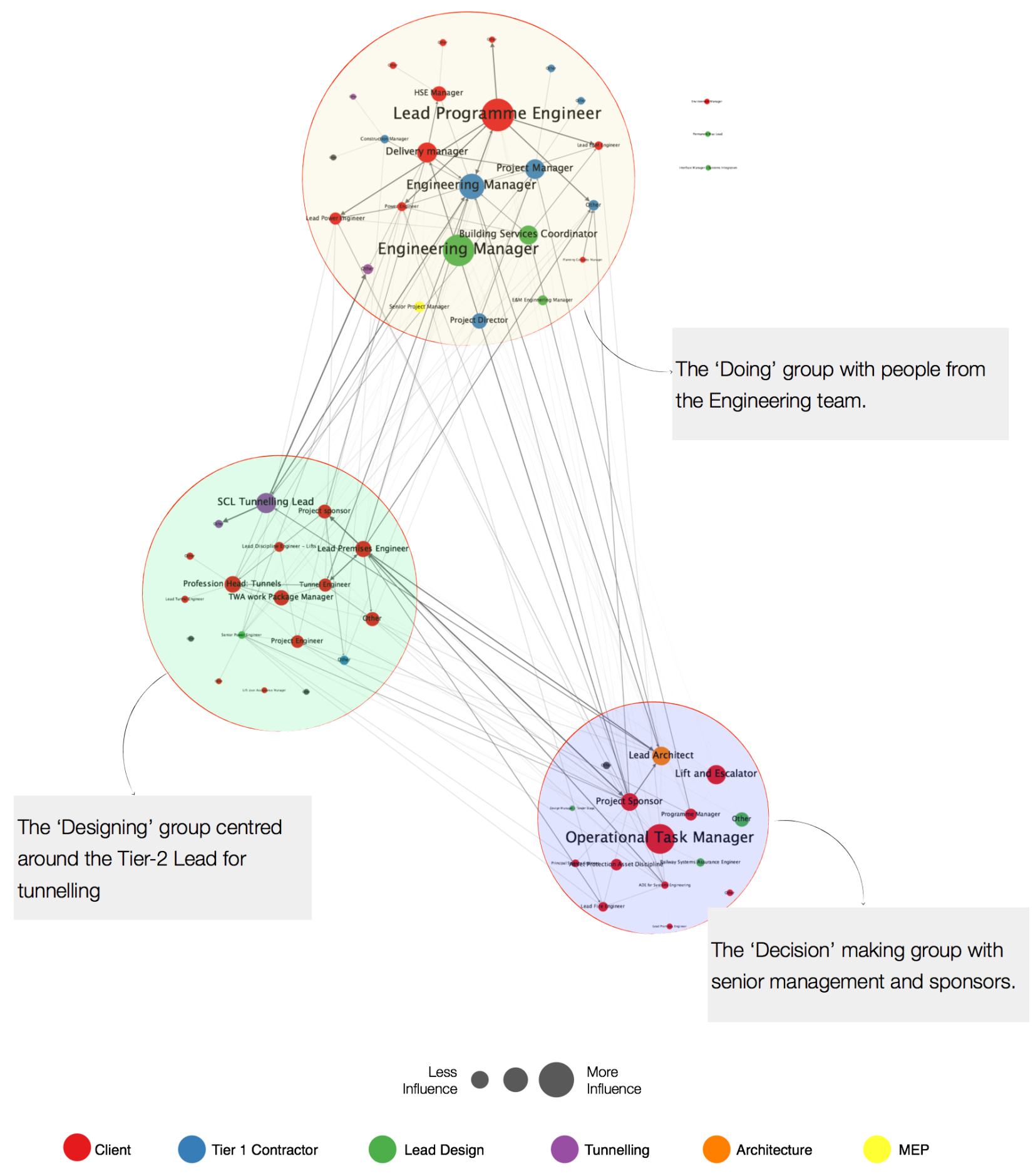

Figure 7: Communities' substructure within the network.

[ 

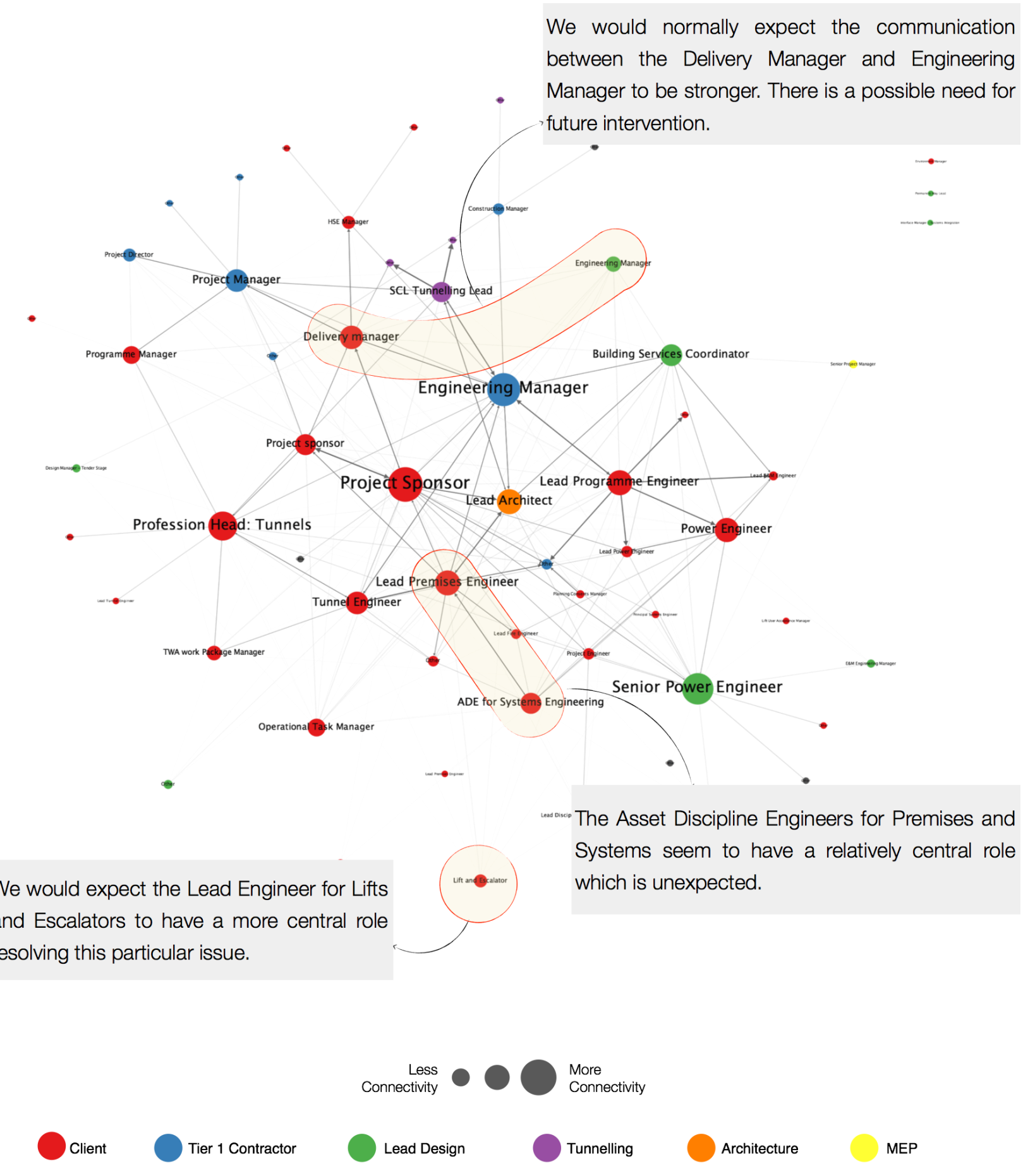

Figure 8: Connectivity of actors within the information exchange network 


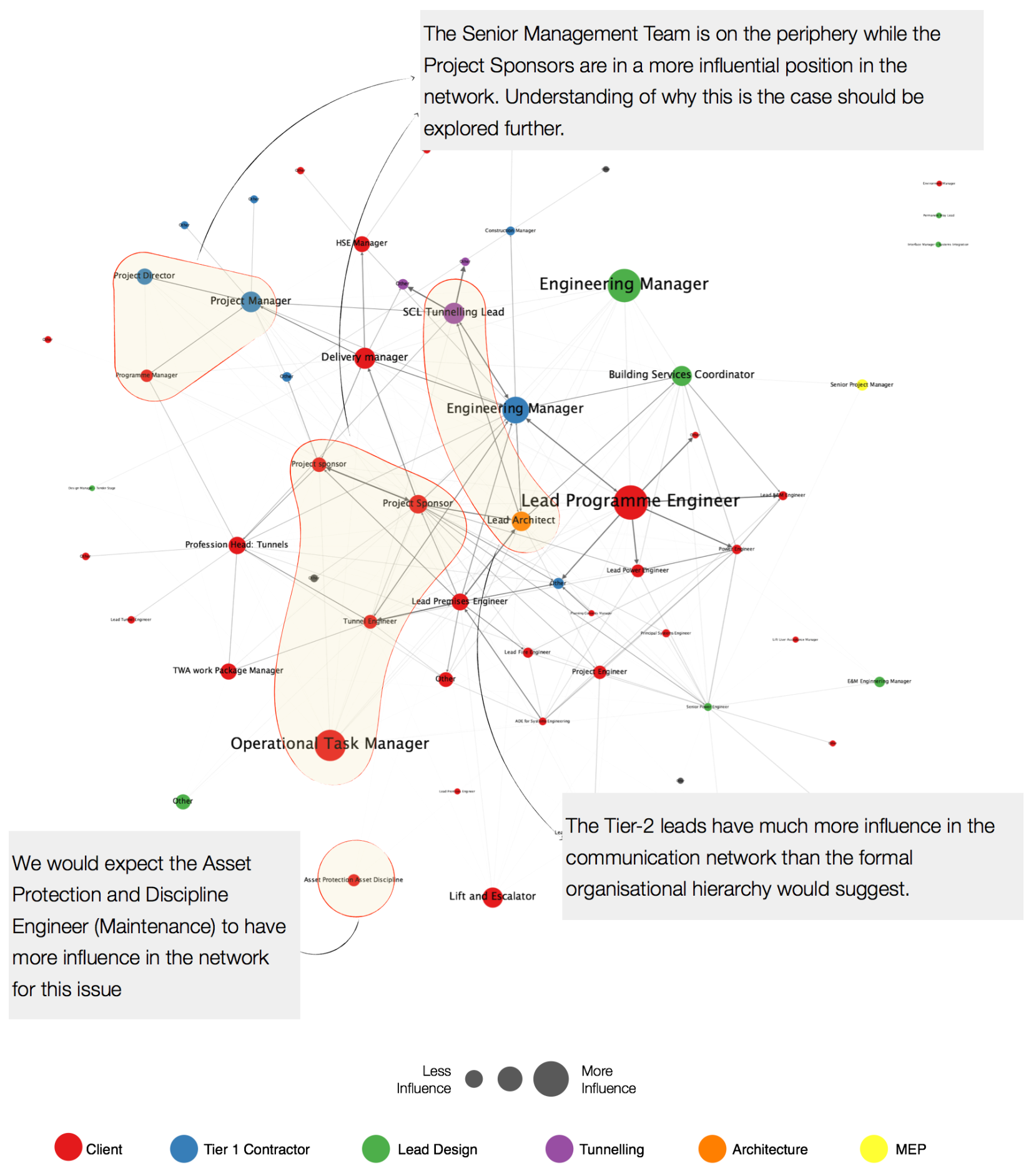

Figure 9: Influence of actors within the information exchange network 


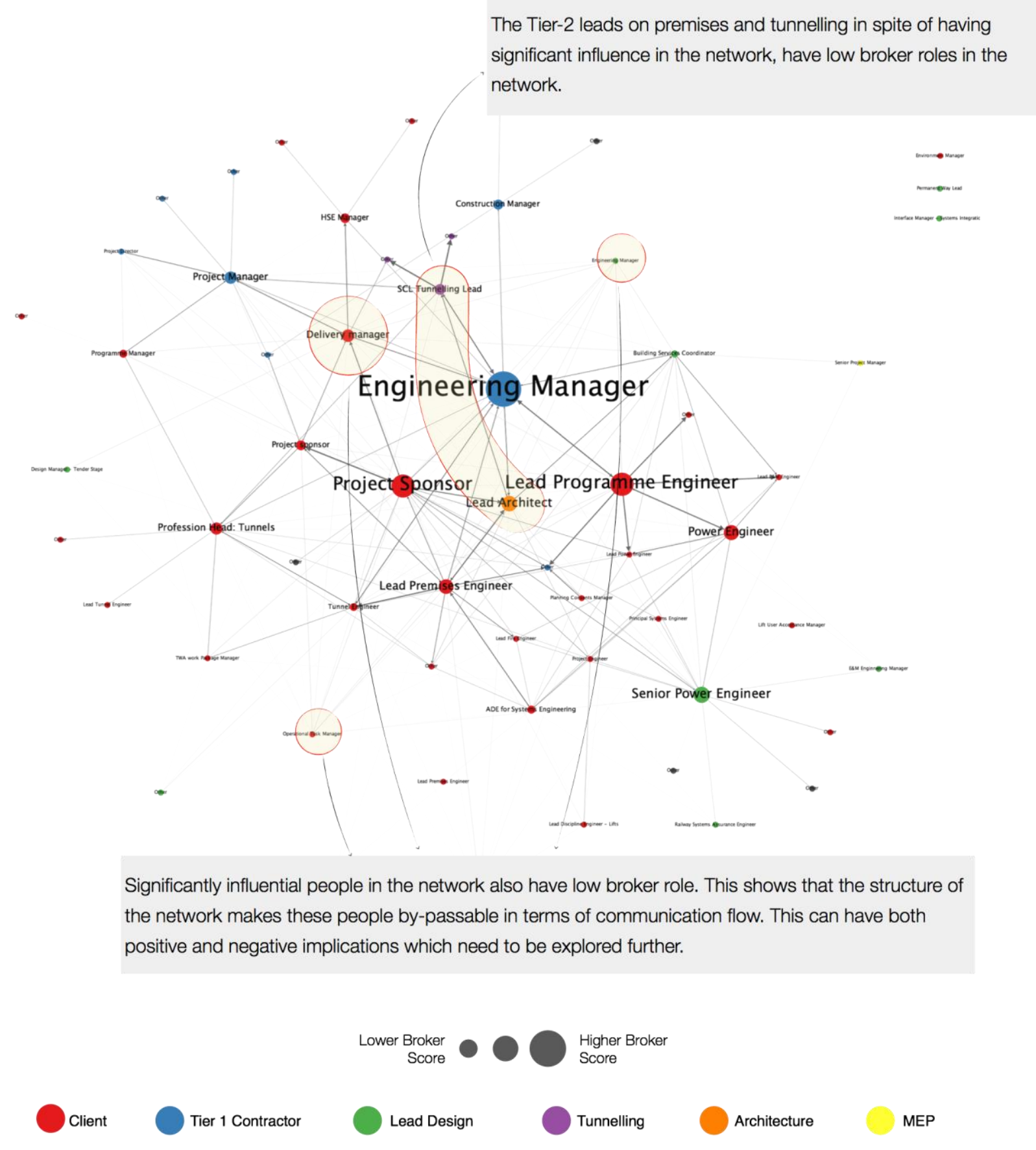

Figure 10: Brokerage potential of actors within the information exchange network 


\section{CONCLUSION}

This study employed the literature of social networks to argue the need to acknowledge the power of project-delivery network relationships as a form of governance in complex, transient project organisations, complementing, or acting as a substitute, to the formal hierarchical and contractual structures (Bechky, 2006; Di Vincenzo and Mascia, 2012). The effective and efficient functioning of the network requires that the communication ties are optimum, particularly in terms of strengths and direction, in relation to the functions of the network. It also requires coordinating actors, establishing and maintaining connections that are critical for the flow of communication among network members.

Our study has yielded a number of important findings. First of all, we have shown that the network of communication in resolving issues within a project could significantly differ from the formal organisational hierarchies defined by the organisations. We also identified that this multidisciplinary, inter-organisational network shows a core-periphery network with a number of 'small world' properties, which allows it to be efficient in connecting all network actors. Most importantly the networks showed hidden 'community' structure with actors joined together in densely connected groups with looser connections to other parts of the network. These communities followed themes of decision, design and implementation moving beyond the borders of organisation and functional disciplines. Significantly, these three self-organising communities are not reflected in the contractual project governance. We also demonstrated that by examining the centralities of the actors in the network we could identify the problems in the network, validate the good aspects in the organisation and identify interesting correlations, such as the positions of 
senior management team and sponsors corresponding to the project life cycle, which could be explored further.

In conclusion, our study has illustrated the appropriateness of the network approach in the study of the functioning of large infrastructure project networks. SNA is of immediate relevance to project managers as it will not only reveal dysfunctions in the project network but also allows for the development of remedies and support the development of collaborative activities among network members. Indeed, network-based interventions could be developed to help managers design their team structures to facilitate successful delivery of projects through more reliable decision making and therefore reducing project uncertainty and enhancing project value. Arguably, there needs to be a move away from the focus on dyadic contractual relationships between firms towards a network management and governance approach.

Finally, a number of important limitations need to be considered. First, our study took a 'snapshot' of the project at a particular point of its development. However, project networks are dynamic and continuously evolving. Future studies should therefore investigate the dynamics of large infrastructure project networks longitudinally. Second, the inability to reach $100 \%$ response rate may have resulted in a false representation of the actual project relationships. Finally, there is a particular finding, which we believe will require further investigation. The observation that project team members often cluster in small densely connected problem-solving groups that are sparsely connected to other parts of the network. Future research may identify the characteristics of such clusters and contribute to a deeper understanding of the self-organizing mechanisms of large infrastructure project networks. 


\section{REFERENCES}

Alojairi, A. and Safayeni, F. (2012). The dynamics of inter-node coordination in social networks: a theoretical perspective and empirical evidence. International Journal of Project Management 30, 15-26.

Balkundi, P. and Harrison, D.A. (2006). Ties, leaders, and time in teams: strong inference about network structure's effects on team viability and performance. Academy of Management Journal 49, 49-68.

Beal, D. J., Cohen, R. R., Burke, M. J., and McLendon, C. L. (2003). Cohesion and performance in groups: A meta-analytic clarification of construct relations. Journal of Applied Psychology, 88(6), 989.

Bechky, B.A. (2006). Gaffers, gofers, and grips: role-based coordination in temporary organisations. Organisation Science 17, 3-21.

Bonacich, P. (1987). Power and Centrality: A Family of Measures. American Journal of Sociology, 92, 1170-1182.

Borgatti, S.P. (2005). Centrality and network flow. Social Networks. 27(1): 55-71.

Borgatti, S.P. and Foster, P.C. (2003). The network paradigm in organisational research: a review and typology. Journal of Management 29, 991-1013.

Bosch-Rekveldt, M., Jongkind, Y., Mooi, H., Bakker, H., and Verbraeck, A. (2011). Grasping project complexity in large engineering projects: The TOE (Technical, Organisational and Environmental) framework. International Journal of Project Management, 29(6), 728-739.

Brandes, U. (2001), A Faster Algorithm for Betweenness Centrality. Journal of Mathematical Sociology 25(2):163-177. 
Brass, D.J., Galaskiewicz, J., Greve, H.R. and Tsai, W. (2004). Taking stock of networks and organisation: a multilevel perspective. Academy of Management Journal 47, 795-817.

Chowdhury, A. N., Chen, P. H., and Tiong, R. L. (2011). Analysing the structure of public-private partnership projects using network theory. Construction Management and Economics, 29(3), 247-260.

Coleman, J.S. (1988). Social capital in the creation of human capital. The American Journal of Sociology 94, S95-S120 (Supplement).

Contractor, N.S., Wasserman, S. and Faust, K. (2006). Testing multitheoretical hypothesis about organisational networks: an analytic framework and empirical evidence. Academy of Management Review 31, 681-703.

Cross, R., Borgatti, S. P. and Parker, A. (2002). Making invisible work visible: Using social network analysis to support strategic collaboration. California management review, 44(2), $25-46$.

Cross, R. and Parker, A. (2004). The Hidden Power of Social Networks. Understanding How Work Really Gets Done in Organisations. Harvard Business School Publishing, Boston.

Csardi G and Nepusz T (2006). The igraph software package for complex network research, International Journal of Complex Systems 1695. 2006. http://igraph.org

Di Vincenzo, F. and Mascia, D., (2012). Social capital in project-based organisations: its role, structure, and impact on project performance. International Journal of Project Management $30,5-14$

Donaldson, L. (2001). The contingency theory of organisations. Thousand Oaks, CA: Sage Publications. 
Dubois, A. and Gadde, L. E. (2002), The Construction Industry as a Loosely Coupled System: Implications for Productivity and Innovation, Construction Management and Economics, 20, pp. 621-31.

El-Sheikh, A. and Pryke, S. D. (2010), Network gaps and project success, Construction Management and Economics, 28(12): 1205-1217.

Engwall, M. (2003). No project is an island: linking projects to history and context. Research Policy $32,789-808$.

Evans, C. R., and Dion, K. L. (2012). Group cohesion and performance a meta-analysis. Small Group Research, 43(6), 690-701.

Flyvbjerg, B. (2009). Survival of the unfittest: why the worst infrastructure gets built-and what we can do about it. Oxford review of economic policy, 25(3), 344-367.

Freeman, L.C. (1979). Centrality in social networks. Conceptual clarification. Social Networks 1, 215-239.

Freeman, L.C. (2004). The Development of Social Network Analysis: A Study in the Sociology of Science. Empirical Press, Vancouver.

Granovetter, M. (2005). The impact of social structure on economic outcomes. The Journal of Economic Perspectives 19, 33-50.

Hanisch, B. and Wald, A. (2011). A project management research framework integrating multiple theoretical perspectives and influencing factors. Project Management Journal 42, 4-22.

Hossain, L. (2009). Effect of organisational position and network centrality on project coordination. International Journal of Project Management 27, 680-689.

Hossain, L. and Wu, A. (2009). Communications network centrality correlates to organisational coordination. International Journal of Project Management 27, 795-811. 
Jacomy M, Venturini T, Heymann S. and Bastian M (2014) ForceAtlas2, a Continuous Graph Layout Algorithm for Handy Network Visualization Designed for the Gephi Software. PLoS ONE 9(6): e98679. doi: 10.1371/journal.pone.0098679.

Kadushin, C. (2011). Understanding Social Networks: Theories, Concepts, and Findings. New York: Oxford University Press.

Knoke, D. and Young, S. (2008) Social Network Analysis, 2nd edition, CA: Sage Publications.

Kratzer, J., Leenders, R.T.A.J. and Van Engelen, J.M.L. (2010). The social network among engineering design teams and their creativity: a case study among teams in two product development programs. International Journal of Project Management 28, 428-436.

Loosemore, M. (1999) Responsibility, power and construction conflict. Construction Management and Economics, 17, 699-709.

Love, P. E. D., Holt, G. D., Shen, L. Y., Li, H., and Irani, Z. (2002). Using systems dynamics to better understand change and rework in construction project management systems. International Journal of Project Management, 20(6), 425-436.

McCulloh, I., Armstrong, H., and Johnson, A. (2013). Social Network Analysis with Applications. John Wiley and Sons

Meng, X. (2012). The effect of relationship management on project performance in construction. International Journal of Project Management 30, 188-198.

Ouwerkerk, S. (2001) A network analysis based audit trail of a principal contractors' project life cycle process risk- risk identification and management in principal contracting, MSc thesis, Faculty of the Built Environment, South Bank University. 
Pauget, B. and Wald, A. (2013). Relational competence in complex temporary organisations: The case of a French hospital construction project network. International Journal of Project Management, 31(2), 200-211.

Pons, P. and Latapy, M. (2014): Computing communities in large networks using random walks, available online: http://arxiv.org/abs/physics/0512106.

Pryke, S.D. (2004) Analysing construction project coalitions exploring the application of social network analysis in construction. In Construction Management and Economics, Vol.22, No.8, Oct 2004, pp 787-797.

Pryke, S.D. (2005) Towards a social network theory of project governance. Construction Economics and Management, 23 (9), 927-39.

Pryke, S.D. (2012) Social Network Analysis in Construction, Oxford: Blackwell Publishing Ltd.

Wasserman, S., Faust, K. (1994). Social Network Analysis. Methods and Applications. Cambridge University Press, New York.

Winter, M., Smith, C., Morris, P. and Cicmil, S. (2006). Directions for future research in project management: the main findings of a UK government funded research network. International Journal of Project Management 24, 638-649.

West, D.B. (1996). Introduction to Graph Theory. Upper Saddle River, N.J.: Prentice Hall.

Wise, S. (2014). Can a team have too much cohesion? The dark side to network density. European Management Journal, 32, 5, 703-711. 